\title{
Effects of hypoxia storage on gene transcript accumulation during tomato fruit ripening
}

\section{Camila Pegoraro', Railson Schreinert dos Santos², Mariana Madruga Krüger', Aline Tiecher ${ }^{3}$, Luciano Carlos da Maia ${ }^{1}$, Cesar Valmor Rombaldi ${ }^{3}$, Antonio Costa de Oliveira ${ }^{1 *}$}

\author{
1Plant Genomics and Breeding Center, Eliseu Maciel School of Agronomy, Universidade Federal de Pelotas, \\ Pelotas, RS, Brazil. \\ ${ }^{2}$ Technological Development Center, Universidade Federal de Pelotas, Pelotas, RS, Brazil. \\ ${ }^{3}$ Department of Agroindustrial Science and Technology, Eliseu Maciel School of Agronomy, Universidade Federal \\ de Pelotas, Pelotas, RS, Brazil.
}

*Corresponding author: acostol@terra.com.br

Received: December 18, 2011; Accepted: July 05, 2012

\begin{abstract}
Tomato (Solanum lycopersicum L.) is a climacteric fruit, i.e., during ripening an increase in ethylene synthesis and high rate of respiration are observed. Low oxygen levels might inhibit or block ethylene biosynthesis and therefore retard the ripening process. Despite commercial applications of low oxygen treatments, the precise mode of action of low oxygen in fruit tissues and ripening is not well understood. In order to delineate the molecular responses to low oxygen stress in fruits, hypoxia-responsive tomato genes encoding heat shock factors, heat shock proteins, and enzymes involved in fermentation and ethylene synthesis pathways were analyzed. In this study, tomato fruit stored under hypoxia conditions showed that HSP17.7 and HSP21 genes were highly induced by low oxygen level, indicating their primary role in maintaining cellular homeostasis after this stress.
\end{abstract}

Keywords: gene expression, heat shock proteins, Solanum lycopersicum.

Abbreviations: ACC: 1-amino-cyclopropane-1-carboxylic acid; ACS: 1-amino-cyclopropane-1-carboxylic acid synthase; ACO: 1-amino-cyclopropane-1-carboxylic acid oxidase; ADH: alcohol dehydrogenase; CT: Cycle Threshold; HSF: heat shock factor; HSP: heat shock protein; LDH: lactate dehydrogenase; MeV: MultiExperiment Viewer; PCR: polymerase chain reaction; PDC: pyruvate decarboxylase; RT: room temperature.

\section{INTRODUCTION}

Tomato (Solanum lycopersicum L.) is a model plant species and is the second most important vegetable crop, given its use as a model for fruit molecular pathway, development and ripening studies (Vidoz et al., 2010; Centeno et al., 2011). Also, it is a frequent component of the human diet due to its high antioxidant and vitamin contents (Wang et al., 2009) and its versatile culinary use (León-Sánchez et al., 2009). Tomato is a climacteric fruit, i.e., its ripening is strongly associated with the increase in respiration and ethylene activity. The synthesis of ethylene is coordinated by multigene families involved in ACC metabolism. The ACS (EC 4.4.1.14) and ACO (EC 1.14.17.4), specially ACS2, ACS4 and AC01 appear to play important roles in climacteric fruit ethylene production (White, 2002; Barry and Giovannoni, 2007). The final biosynthetic step of ethylene requires molecular oxygen, which allows the ACO action in the conversion of ACC to ethylene. In this sense, by acting directly on this last step, a lower oxygen concentration might result in an inhibition or blocking of ethylene biosynthesis. Thus, for a variety of fruits, the 
storage under hypoxia condition is routinely used to slow the ripening process (Ramonell et al., 2002).

Some commercial practices, such as wax coatings and plastic liners are used to limit the oxygen availability (Pasentsis et al., 2007). Despite these commercial applications of low oxygen treatments, the precise mode of action of low oxygen in fruit tissues and ripening is not well understood.

Previous studies showed that the application of low oxygen levels (2.5 to $5.5 \%$ ) suppressed the induction of ripening enzymes (Kanellis et al., 1991). In addition, analysis of mRNA in preclimacteric fruits revealed that low oxygen levels induce new mRNA species, suggesting a complex stress response involving more than a simple adaptation change in energy metabolism (Loulakakis et al., 2006).

Fermentative pathways play an important role in plant responses to anoxia, i.e., enzymes such as $A D H$ (EC 1.1.1.1) and PDC (EC 4.1.1.1) in ethanol fermentation, as well as LDH (EC 1.1.1.27) in lactic acid fermentation are key to these responses (Tadege et al., 1999; Ismond et al., 2003; Bieniawska et al., 2007). In addition, heat-related genes, including those coding for HSFs and HSPs have been shown to be present in transcript profiles of plants under anoxia stress (Loreti et al., 2005; Banti et al., 2010).

In order to link responses to hypoxia at the molecular level and the onset of ripening in tomato fruits, the expression profiles of 12 genes putatively involved in signaling response pathways described above were analyzed.

\section{MATERIAL AND METHODS}

Plant material: Tomato fruits (Solanum lycopersicum cv. FlavorTop) harvested at breaker stage were stored in two conditions: hypoxia and normoxia. In normoxia, fruits were stored at $\mathrm{RT}\left(23^{\circ} \mathrm{C}\right.$ and relative humidity of $75 \%$ ) with samples collected at $0(\mathrm{~N}), 1$ (N-1d), 3 (N-3d) and 5 (N-5d) days after harvest. Under hypoxia, fruits were placed in glass containers bearing low levels of $\mathrm{O}_{2}(0.6 \mathrm{kPa})$ and stored at RT for 3 days. After, the fruits were transferred to normoxia conditions, with samples collected at $0(\mathrm{H}), 1(\mathrm{H}-1 \mathrm{~d}), 3(\mathrm{H}-3 \mathrm{~d})$ and $5(\mathrm{H}-5 \mathrm{~d})$ days after hypoxia. Fruits were subjected to hypoxia environment using a $0.5 \mathrm{~L}$ glass jar flushed with $100 \% \mathrm{~N}_{2}$. Normoxia and hypoxia treatments were performed in the dark. Three biological replicates were performed for each treatment, and each replicate consisted of five fruits. After each period, tomato fruits were collected, their color was measured and they were immediately frozen in liquid $\mathrm{N}_{2}$ and stored at $-80^{\circ} \mathrm{C}$ until the moment of total RNA extraction.

Color: The color changes during ripening in both normoxia and hypoxia conditions were evaluated using a Minolta colorimeter CR-300, with illuminating D65 and aperture $8 \mathrm{~mm}$, with parameters $L^{*}, a^{*}$ and $b^{*}$ (CIELab) (Konica Minolta, Osaka, Japan). There were two readings on opposite sides of each of the five fruits. Results were expressed in hue color angle $\left(h^{\circ}\right)$, by the equation $\mathrm{h}^{0}=\tan -1 \mathrm{~b} * / \mathrm{a}$ (McGuire, 1992). Data were tested for normality and homoscedasticity and later subjected to an analysis of variance $(p \leq 0.05)$. The effect of time within each treatment was evaluated by the Tukey test $(p \leq 0.05)$ and the effect of time between treatments was evaluated by the $t$ test $(p \leq 0.05)$.

qPCR analysis: A set of 12 genes (Table 1) was evaluated. Sequences were obtained from the National Center for Biotechnology Information (http://www.ncbi.nlm.nih.gov/) and Sol Genomic Network (http://solgenomics.net/). Primer design was performed using the Vector ${ }^{\mathrm{TM}}$ Software (Invitrogen ${ }^{\circledR}$, Carlsbad, California, United States). The criteria used for primer selection was according to recommendations of the manufacturer (Applied Biosystems ${ }^{\circledast}$, Foster City, California, United States). Total RNA was extracted from $0.1 \mathrm{~g}$ of pericarp tissue from a pool of tomato fruits using PureLink ${ }^{\mathrm{TM}}$ Plant RNA Reagent (Invitrogen ${ }^{\circledR}$ ), followed by treatment with DNAse $\mathrm{I}^{\mathrm{TM}}$ (Invitrogen ${ }^{\circledR}$ ) according to manufacturer's instructions. The quantity and the quality of RNA were assessed by spectrophotometer, agarose gel $(2 \% \mathrm{w} / \mathrm{v})$ and PCR. cDNAs were obtained from $2 \mu \mathrm{g}$ of RNA using SuperScript III FirstStrand System for RT-PCR (Invitrogen ${ }^{\circledR}$ ).

qPCR amplification was made in a 7500 Fast RealTime PCR Systems (Applied Biosystems ${ }^{\circledR}$ ). Conditions for the amplification reaction were as follows: two min at $50^{\circ} \mathrm{C}$, followed by $10 \mathrm{~min}$ at $95^{\circ} \mathrm{C}$, then 40 cycles at $\left(95^{\circ} \mathrm{C}\right.$ for 30 seconds/ $59^{\circ} \mathrm{C}$ for 1 minute/ $72^{\circ} \mathrm{C}$ for 1 minute), and a final extension at $72^{\circ} \mathrm{C}$ for $5 \mathrm{~min}$, following a standard dissociation curve. A CT was obtained, and the relative expression level was calculated based on the exponential region of the PCR reaction curve (Applied Biosystems ${ }^{\circledR}$ ). For each gene analyzed, the Ubiquitin gene was used as an endogenous control to quantify CDNA abundance. CT was obtained during the reaction cycles, and $\triangle \triangle C T$ was calculated based on the exponential PCR reaction using REL = 2- ${ }^{-\Delta C T}$ (Livak and Schimittgen, 2001). Gene expression data was analyzed using MeV software and presented as a heat map diagram using the harvest stage as a baseline (Saeed et al., 2003). 
Cellular localization of genes studied: Identification of the $\mathrm{N}$-terminal region of each amino acid sequence was made using the software Target $P$ 1.1 Server (http://www.cbs.dtu.dk/services/TargetP/). Target $P$ is able to predict the location based on the presence of any of the $\mathrm{N}$-terminal chloroplast transit peptide, mitochondrial targeting peptide or secretory pathway signal peptide pre-sequences (Nielsen et al., 1997; Emanuelsson et al., 2000).

\section{RESULTS}

The ripening process occurred in fruits under normoxia, with fruit color changes from green to red (Figure 1, Table 2). The same changes were observed in fruits after hypoxia storage however the process was delayed in 3 days (storage time). In addition, during the 5th day after hypoxia storage (8 days after harvest), fruits showed higher values of $\mathrm{h}^{0}$ (hue angle) when compared to the 5 th day after harvest.

Table 1. List of specific primers used for quantitative polymerase chain reaction analysis of candidate genes.

\begin{tabular}{lccc}
\hline Primers & Identification & Forward & Reverse \\
\hline PDC & Solyc02g077240* & AACAATGCCATCGGTTCCACG & AAGTTGAAGTCGCCGGGAACC \\
ADH & Solyc01g087640 & TACTGTCAACGCCACTGTTCGGA & TCATTCGCTCCATCAAGGCCTAG \\
LDH & Solyc08g078850 & CGGAAACGTCGGTATGGCAAT & GGATCTTCGTACGCGGCAGAA \\
AC01 & gi: $1054800^{*}$ & TCCACCATGTCCTAAGCCCGA & CGCATGGGAGGAACATCGATC \\
HSFA3 & gi: 264666930 & TTGAGTTGCAGCAGCAGCAGC & GCCGAACACGAGCCAAGAATG \\
HSP17.6 & gi: 1773290 & ATGATGGAAGCTGCCGGTGAA & GCCATGGCCTTAGCATCACGA \\
HSP17.7 & gi: 4836468 & GATCGACGAAGCAGCAGCATG & TGGCAAATGCAGAGCTCTCCC \\
HSP21 & gi: 1518138 & TCGTTCCGTCGATGAGAAGGC & CGGCAGTGCCTTGGTTGTTTC \\
HSP23.6 & gi: 3492853 & ATGACCAGGATGATCGTGGCG & AAAGCATCACGGCGAGAGACG \\
HSP70 & Solyc06g076020 & ATCATGTTGCCAAACGCCGAC \\
HSP90 & Solyc06g036290 & ATCCGGTTCGAGAGCTTGACG & TCAGGCTGCGCATCGAGTTTA \\
HSP110 & Solyc02g088610 & TACGGCGCTGAATGGGATGAA \\
UBI & gi: $19396^{*}$ & TTTCCGGCGTACAGTTTTGCG & CGAAGCCTCTGAACCTTTCCA \\
\hline
\end{tabular}

*Sequence obtained from Sol Genomic Network (http://solgenomics.net/); ${ }^{*}$ sequence obtained from National Center for Biotechnology Information (http://www.ncbi.nlm.nih.gov/); " primers obtained from Maloney et al., 2010.

PDC: pyruvate decarboxylase; ADH: alcohol dehydrogenase; LDH: lactate dehydrogenase; AC01:1-amino-cyclopropane-1-carboxylic acid oxidase HSFA3: heat shock factor; HSPs: heat shock protein 70, 90 and 110; sHSPs: small heat shock protein 17.6, 17.7, 21 and 23.6; UBI: ubiquitina.

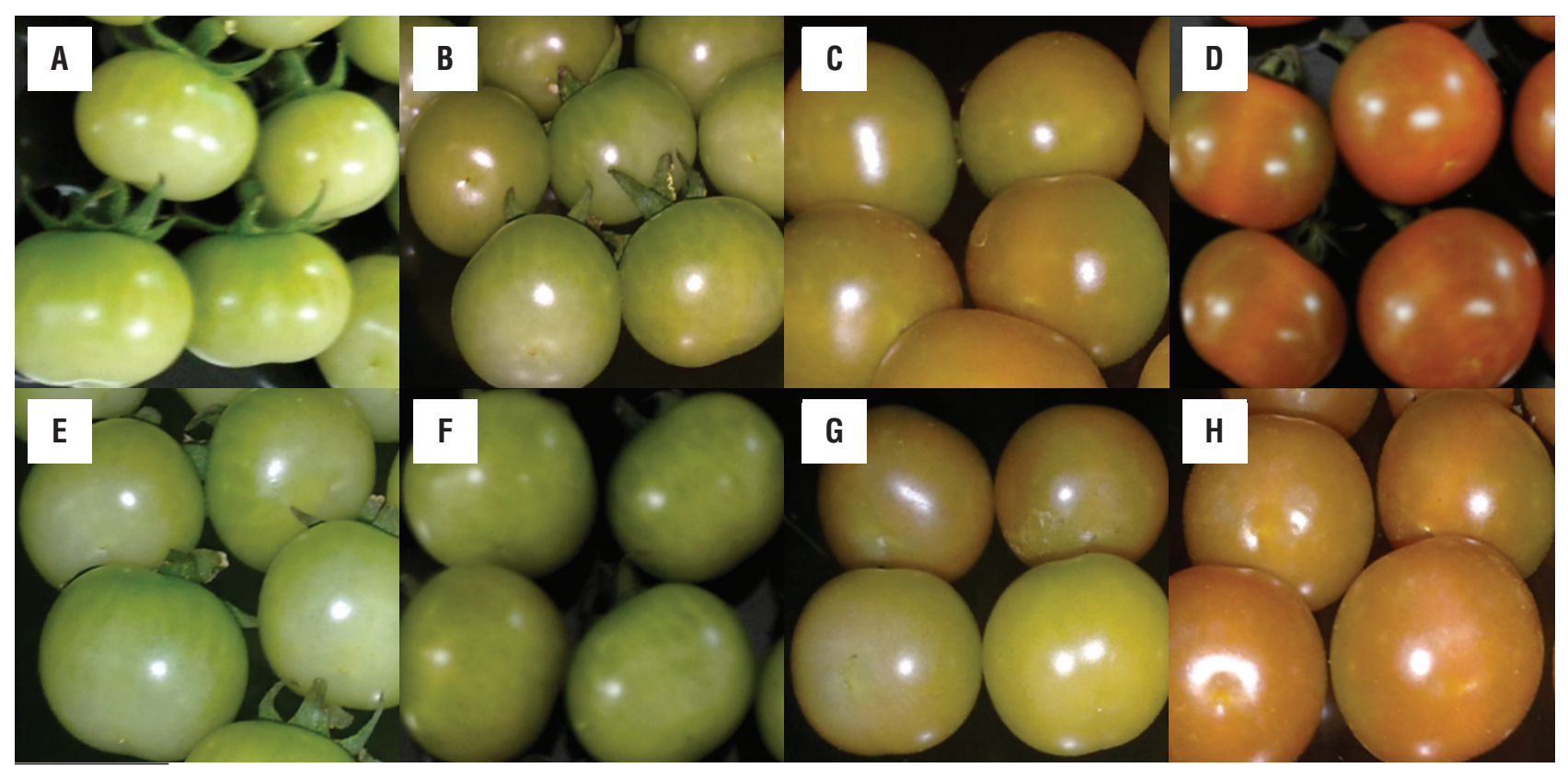

Figure 1. Skin color of tomato fruits in normoxia and hypoxia conditions. (A) Harvest/Normoxia (N). (B) Normoxia +1 day (N-1d). (C) Normoxia +3 days $(\mathrm{N}-3 \mathrm{~d})$. (D) Normoxia +5 days $(\mathrm{N}-5 \mathrm{~d})$. (E) Hypoxia during 3 days $(\mathrm{H})$. (F) After Hypoxia +1 day $(\mathrm{H}-1 \mathrm{~d})$. $(\mathrm{G})$ After Hypoxia +3 days $(\mathrm{H}-3 \mathrm{~d})$. ( $\mathrm{H})$ After Hypoxia +5 days $(\mathrm{H}-5 \mathrm{~d})$. 
Table 2. Skin color of tomato fruits in normoxia and hypoxia conditions.

\begin{tabular}{lcc}
\hline \multirow{2}{*}{ Day } & \multicolumn{2}{c}{ Hue color angle $^{\#}$} \\
\cline { 2 - 3 } & Normoxia & After three days of hypoxia $^{111.25 \mathrm{a}^{\text {ns }}}$ \\
\hline 0 & $113.75 \mathrm{a}^{*}$ & $110.89 \mathrm{a}^{\ddagger}$ \\
1 & $97.18 \mathrm{~b}^{\text {ns }}$ & $96.24 \mathrm{a}$ \\
3 & $71.12 \mathrm{c}^{*}$ & $80.95 \mathrm{c}$ \\
5
\end{tabular}

*Hue color angle: $0^{\circ}=$ red, $90^{\circ}=y e l l o w, 180^{\circ}=$ green, $360^{\circ}=$ blue; $\neq$ means followed by same letters in the column did not differ by the Tukey test $(p \leq 0.05)$; ns and *nonsignificant and significant, respectively, by the $t$-test $(p \leq 0.05)$ comparing normoxia and hypoxia in each day.
The expression profiles of genes encoding three enzymes that act in fermentation pathways (ADH, PDC and LDH), one enzyme involved in ethylene synthesis (AC01), one HSF (HSFA3), three HSPs (HSP70, HSP90 and HSP110) and four small HSPs (HSP17.6, HSP17.7, HSP21 and HSP23.6) were affected by hypoxia stress in tomato fruits (Figure 2). The genes evaluated could be divided in relative low (0-2.5X), medium (0-15X) and high expression (0-750X), according to their fold increase. Genes with a relative low expression were the majority (7/12), followed by medium expression genes (3/12) and highly expressed genes (2/12).
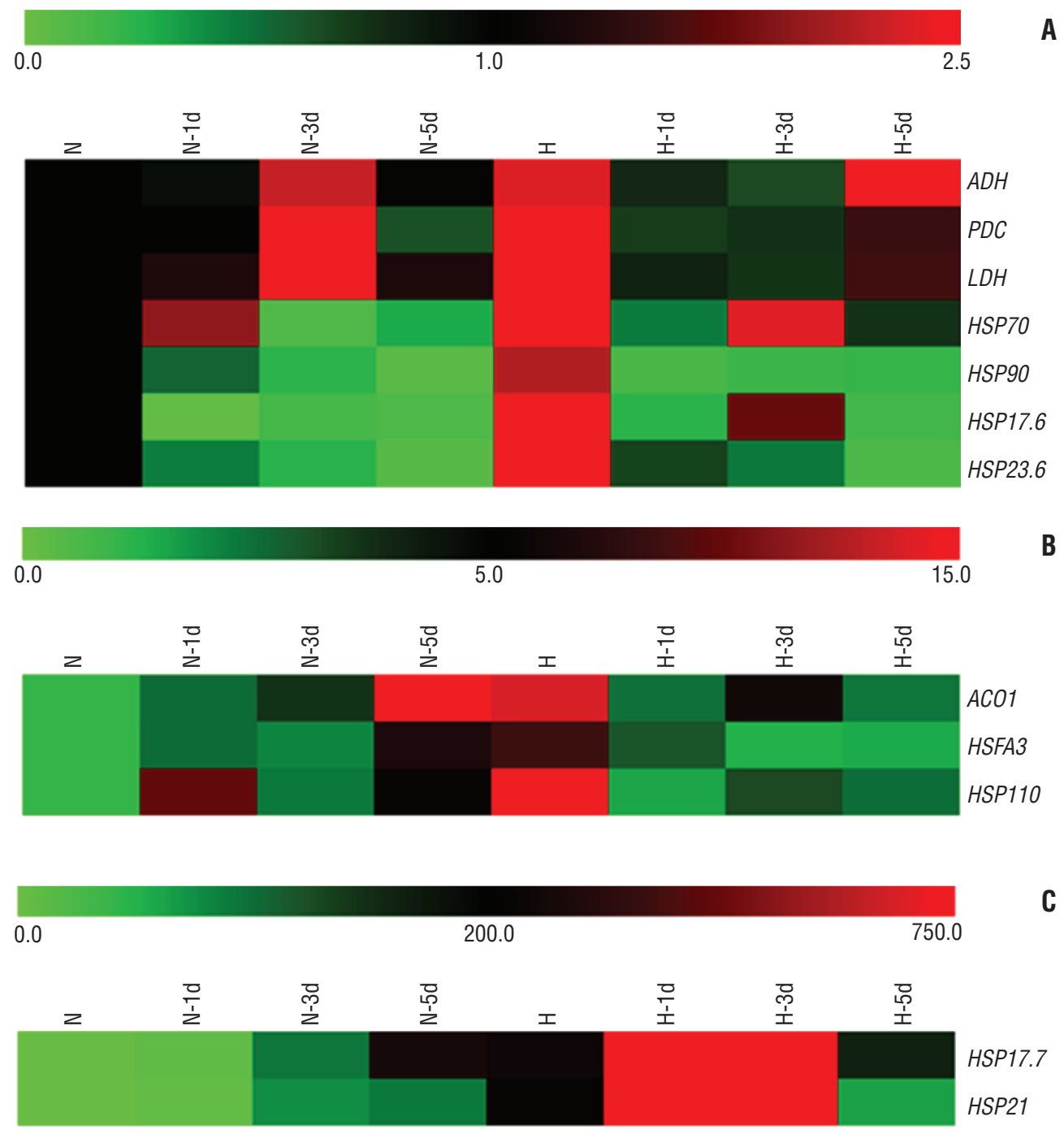

Figure 2. Relative mRNA abundance in FlavorTop tomato (Solanum lycopersicum) fruit. mRNA abundance is represented at different scales, using the MultiExperiment Viewer (TIGR MeV) software (Saeed et al., 2003). mRNA abundance of each gene from $\mathrm{N}$ (Harvest/Normoxia) served as the baseline for determining relative RNA levels, in which N-1d: Normoxia + 1 day, N-3d: Normoxia +3 days, N-5d: Normoxia +5 days. H: Hypoxia during 3 days, $\mathrm{H}-1 \mathrm{~d}$ : after hypoxia +1 day, $\mathrm{H}-3 \mathrm{~d}$ : after hypoxia +3 days and $\mathrm{H}-5 \mathrm{~d}$ : after hypoxia + 5 days. Genes used in this study were ADH (alcohol dehydrogenase), PDC (pyruvate decarboxylase), LDH (lactate dehydrogenase), AC01 (1-amino-cyclopropane-1-carboxylic acid oxidase), HSFA3 (heat shock factor), HSPs (heat shock protein 70, 90 and 110), and SHSPs (small heat shock protein 17.6, 17.7, 21 and 23.6). 
In the three genes encoding enzymes involved in fermentation pathways (PDC, ADH and LDH) (Figure 2A) increased transcript levels were observed in $\mathrm{N}-3 \mathrm{~d}, \mathrm{H}$ and $\mathrm{H}-5 \mathrm{~d}$. Transcript levels of the ACO1 gene (Figure 2B) showed a linear increase during the course of normal ripening in normoxia conditions. Transcript levels of this gene were also shown to increase immediately after storage under hypoxia and decrease after this condition, indicating a lower ethylene production.

The transcript levels of HSFA3 (Figure 2B) were highly accumulated in $\mathrm{N}-5 \mathrm{~d}$, at the end of the maturation cycle. This transcription factor was also induced immediately after storage under hypoxia, and the transcript levels were reduced when fruits were removed to ripen under normoxia.

The genes that encode HSPs of high molecular weight showed variable expression (Figures $2 \mathrm{~A}$ and $\mathrm{B}$ ). HSP70 showed higher transcript accumulation levels at $\mathrm{N}-1 \mathrm{~d}, \mathrm{H}$ and $\mathrm{H}-3 \mathrm{~d}$. HSP90 linearly decreased during normal ripening under normoxia and presented high transcript levels immediately after hypoxia storage. HSP110 was expressed at $\mathrm{N}-1 \mathrm{~d}$ and showed a slight increase at $\mathrm{N}-5 \mathrm{~d}$. This gene was highly expressed immediately after hypoxia storage, but decreased over time.

HSP17.6 and HSP23.6 exhibited a decrease in transcript accumulations after harvest under normoxia conditions and slightly increased after hypoxia storage (Figure 2A). On the other hand, the genes HSP17.7 and HSP21 were strongly induced by low oxygen levels, ca.750 fold higher than the other two sHSP genes (Figure 2C).

Table 3. Cellular localization of the genes studied.

\begin{tabular}{lcc}
\hline Protein & Localization $^{*}$ & Probability (\%) \\
\hline PDC & Plastid & 82 \\
ADH & Other & 58 \\
LDH & Plastid & 73 \\
AC01 & Other & 91 \\
HSFA3 & Other & 89 \\
HSP17.6 & Other & 87 \\
HSP17.7 & Mitochondrial & 30 \\
HSP21 & Plastid & 87 \\
HSP23.6 & Mitochondrial & 87 \\
HSP70 & Other & 85 \\
HSP90 & Secretory pathway & 44 \\
HSP110 & Plastid & 97 \\
\hline
\end{tabular}

${ }^{*}$ Cellular localization according to the analysis of $\mathrm{N}$-terminal regions performed with the aid of TargetP 1.1 Server software (http://www.cbs. dtu.dk/services/TargetP/) (Nielsen et al., 1997; Emanuelsson et al., 2000). PDC: pyruvate decarboxylase; ADH: alcohol dehydrogenase; LDH: lactate dehydrogenase; AC01:1-amino-cyclopropane-1-carboxylic acid oxidase; HSFA3: heat shock factor; HSPs: heat shock protein 70, 90 and 110; sHSPs: small heat shock protein 17.6, 17.7, 21 and 23.6.
The in silico analyses indicated that four of the 12 genes studied encode proteins resident in the plastids (PDC, LDH, HSP21 and HSP110), two encode a protein resident in mitochondria (HSP17.7 and HSP23.6) and one encodes a protein resident in secretory pathway (HSP90). The other genes encode proteins that act at other sites in the cell, mainly in the cytosol (Table 3).

\section{DISCUSSION}

Fruit color changes from green to red were observed in fruits under normoxia conditions and in fruits after hypoxia storage. During the 5 th day after hypoxia storage fruits showed higher values of $h^{0}$ when compared to the 5 th day after harvest in normoxia storage. The process of fruit color change has always been strongly linked with ethylene biosynthesis in tomato. During this change, chlorophyll is degraded, there is a breakdown of the photosynthetic apparatus and carotenoids are accumulated (Alexander and Grierson, 2002; Eum et al., 2009). At low oxygen levels, ethylene biosynthesis is decreased (Alexander and Grierson, 2002), delaying ripening and reducing red color development, as observed in this work.

For the genes encoding PDC, ADH and LDH, increased transcript levels were observed in $\mathrm{N}-3 \mathrm{~d}, \mathrm{H}$ and $\mathrm{H}-5 \mathrm{~d}$. These increases in $\mathrm{H}$ were expected since low levels of $\mathrm{O}_{2}$ induce fermentative pathways. The lower expression of ADH, LDH and PDC in $\mathrm{H}-1 \mathrm{~d}$ and $\mathrm{H}-3 \mathrm{~d}$ is due to a return of the aerobic respiration of fruits in the presence of $\mathrm{O}_{2}$, and to a less advanced maturation stage. The induction of $A D H$ in $\mathrm{N}-3 \mathrm{~d}$ and $\mathrm{H}-5 \mathrm{~d}$ is due to the contribution of ADH in the flavor development through the interconversion of aldehyde and alcohol forms of volatile flavors originated from lipids and amino acids during ripening process of fruits (LeónSánchez et al., 2009). The decarboxylation of pyruvate to form acetaldehyde, which is in turn reduced to alcohol by $A D H$, is coordinated by the enzyme PDC, which could explain the high levels of expression of this gene in N-3d and $\mathrm{H}-5 \mathrm{~d}$. The accumulation of LDH transcripts in $\mathrm{N}-3 \mathrm{~d}$ and $\mathrm{H}-5 \mathrm{~d}$ occurred probably due to the need of pyruvate oxidation in the reverse direction aiming a reduction in the accumulation of ethanol.

The AC01 gene showed a linear increase during normal ripening in normoxia conditions and immediately after storage under hypoxia, decreasing after this condition. This behavior after hypoxia suggests a lower ethylene production. This could explain the delay in color change of fruits subjected to hypoxia storage. Reports 
have described that hypoxia or low $\mathrm{O}_{2} / \mathrm{CO}_{2}$ ratio and anaerobic conditions do repress ethylene synthesis and activity in tomato (Paul et al., 2010).

The HSFA3 transcripts were highly accumulated in fruits at the end of the maturation cycle in normoxia condition and immediately after hypoxia storage, and were reduced when fruits were removed to ripen under normoxia. The induction of HSFgenes at low oxygen levels had already been observed in Arabidopsis, and anoxia tolerance in this species is due to the overexpression of HSFA2 (Banti et al., 2010). High expression levels of HSFA3 after hypoxia suggests an important role of this transcription factor in the maintenance of cellular homeostasis after hypoxia stress.

A variable expression in high molecular weight HSP genes was observed. These results suggest that these genes are involved in ripening process and have a small contribution in cellular homeostasis maintenance after hypoxia stress in the tomato fruit. Different HSPs have been identified as ripening-induced genes in tomato (Fei et al., 2004). Previous studies described a ripening regulated small HSP in tomato, which is involved in pectin depolymerization (Ramakrishna et al., 2003), but the role of HSPs in ripening remains poorly understood.

Slight increases in HSP17.6 and HSP23.6 transcript accumulation after hypoxia storage were observed suggesting that these genes are co-regulated under low oxygen levels. The genes HSP17.7 and HSP21 were strongly induced by low oxygen levels. This could mean that HSP17.7 and HSP21 are needed in large amounts to counteract the effects of hypoxia, acting less specifically, and that HSP17.6 and HSP23.6 are needed in lower amounts since they act on a smaller number of molecules. Ramakrishna et al. (2003) described that HSPs act during ripening by protecting the cellular machinery against thermal denaturation during temperature rises in the daytime. The induction of some members of the HSP family by hypoxia stress may be an independent response induced by this condition and it may also be a complex response affecting the whole ripening process. However, this needs further investigations in order to be confirmed. Subsequently, silencing and overexpression studies could be developed to assess the exact function of these genes.

The importance of HSPs in response to stress can be observed in previous reports for other species such as Zea mays L. ssp. mays (Lund et al., 2001), Agrostis stolonifera L. (Heckathorn et al., 2002), Oryza sativa L. (Murakami et al., 2004; Sarkar et al., 2009), Rosa chinensis Jacq. (Jiang et al., 2009), Prunus salicina Lindl.
(Sun et al., 2010), Prunus persica L. Batsch (Pegoraro et al., 2010) and Daucus carota L. (Song et al., 2011), which also reported the induction of HSPS in response to different stresses.

The studied genes encode proteins resident in the plastids (PDC, LDH, HSP21 and HSP110), mitochondria (HSP17.7 and HSP23.6) and secretory pathway (HSP90). The subcellular energy organelles (chloroplast, mitochondria and peroxisomes) in plants are responsible for major metabolic processes including photorespiration, photosynthesis, $\beta$-oxidation, oxidative phosphorylation and the tricarboxylic acid cycle (Taylor et al., 2009). Plastids play an important role in cellular homeostasis, including carbon recycling and pigment, vitamin, aromatic amino acid and hormone biosynthesis. Also, they integrate numerous metabolic pathways that are important in adaptive responses to extreme environmental conditions. This fact can explain the extremely high expression level of the plastid HSP21 gene, as a response to hypoxia stress, seeking for adaptation to this condition. Mitochondria also play a fundamental role under hypoxia conditions, since these organelles are highly sensitive to change oxygen levels due to their dependence on this gas for normal functioning (Dat et al., 2004). Thus, it is believed that the high gene expression of the mitochondrial HSP17.7 gene is a defense mechanism.

Acknowledgements: This work was supported by the Brazilian Ministry of Science and Technology - National Counsel of Technological and Scientific Development (CNPq) and Coordination for the Improvement of High Education Personnel (Capes).

\section{REFERENCES}

Alexander L, Grierson D (2002) Ethylene biosynthesis and action in tomato: a model for climacteric fruit ripening. J. Exp. Bot. 53:2039-2055

Banti V, Mafessoni F, Loreti E, Alpi A, Perata P (2010) The heat-inducible transcription factor hsfa2 enhances anoxia tolerance in Arabidopsis. Plant Physiol. 152:1471-1483.

Barry CS, Giovannoni JJ (2007) Ethylene and fruit ripening. J. Plant. Growth. Regul. 26:143-159.

Bieniawska Z, Barratt DHP, Garlick AP, Thole V, Kruger NJ, Martin C, et al (2007) Analysis of the sucrose synthase gene family in Arabidopsis. Plant J. 49: 810-828.

Centeno DC, Osorio S, Nesi AN, Bertolo ALF, Carneiro RT, Araújo WL, et al (2011) Malate plays a crucial role in starch metabolism, ripening, and soluble solid content of tomato fruit and affects postharvest softening. Plant Cell 23:162-184.

Dat JF, Capelli N, Folzer H, Bourgeade P, Badot PM (2004) Sensing and signalling during plant flooding. Plant Physiol. Biochem. 42:273-282. 
Emanuelsson 0, Nielsen H, Brunak S, Heijne G (2000) Predicting subcellular localization of proteins based on their $\mathrm{N}$-terminal amino acid sequence. J. Mol. Biol. 300:1005-1016.

Eum HL, Ho BK, Choi SB, Lee SK (2009) Regulation of ethylene biosynthesis by nitric oxide in tomato (Solanum lycopersicum L.) fruit harvested at different ripening stages. Eur. Food. Res. Technol. 228:331-338.

Fei ZJ, TangX, Alba RM, White JA, Ronning CM, Martin GB, et al (2004) Comprehensive EST analysis of tomato and comparative genomics of fruit ripening. Plant J. 40:47-59.

Heckathorn SA, Ryan SL, Baylis JA, Wang D, Hamilton EW, Cundiff L, et al (2002) In vivo evidence from a Agrostis stolonifera selection genotype that chloroplast small heat-shock protein can protect photosystem II during heat stress. Funct. Plant Biol. 29:935-946.

Jiang C, Xu J, Zhang H, Zhang X, Shi J, Li M, et al (2009) A cytosolic class I small heat shock protein, RcHSP17.8, of Rosa chinensis confers resistance to a variety of stresses to Escherichia coli, yeast and Arabidopsis thaliana. Plant Cell Environ. 32:1046-1059.

Ismond KP, Dolferus R, De Pauw M, Dennis ES, Good AG (2003) Enhanced low oxygen survival in Arabidopsis through increased metabolic flux in the fermentative pathway. Plant Physiol. 132:1292-1302.

Kanellis AK, Solomos T, Roubelakis-Angelakis KA (1991) Suppression of cellulase and polygalacturonase and induction of alcohol dehydrogenase isoenzymes in avocado fruit mesocarp subjected to low oxygen stress. Plant Physiol. 96:269-274.

León-Sánchez FD, Pelayo-Zaldívar C, Rivera-Cabrera F, Ponce-Valadez M, Ávila-Alejandre X, Fernández FJ, et al (2009) Effect of refrigerated storage on aroma and alcohol dehydrogenase activity in tomato fruit. Postharvest Biol. Technol. 54:93-100.

Livak KJ, Schmittgen TD (2001) Analysis of relative gene expression data using real-time quantitative PCR and the 2(-Delta Delta $\mathrm{C}(\mathrm{T}))$ method. Methods 25:402-408.

Loreti E, Poggi A, Novi G, Alpi A, Perata P (2005) A genome-wide analysis of the effects of sucrose on gene expression in Arabidopsis seedlings under anoxia. Plant Physiol. 137:1130-1138.

Loulakakis K, Hassan M, Gerasopoulos G, Kanellis AK (2006) Effects of low oxygen on in vitro translation products of poly $(A)+$ RNA, cellulase and alcohol dehydrogenase expression in preclimacteric and ripeninginitiated avocado fruit. Postharvest Biol. Technol. 39:29-37.

Lund AA, Rhoads DM, Lund AL, Cerny RL, Elthon TE (2001) In vivo modifications of the maize mitochondrial small heat shock stress protein, HSP22. J. Biol. Chem. 276:29924-29929.

Maloney GS, Kochevenko A, Tieman DM, Tohge T, Krieger U, Zamir D, et al (2010) Characterization of the Branched-Chain Amino Acid Aminotransferase Enzyme Family in Tomato. Plant Physiol. 153:925-936.

McGuire RG (1992) Reporting of objective color measurements. HortScience 27:1254-1255.

Murakami T, Matsuba S, Funatsuki H, Kawaguchi K, Saruyama H, Tanida M, et al (2004) Over-expression of a small heat shock protein, sHSP17.7, confers both heat tolerance and UV-B resistance to rice plants. Mol. Breeding 13:165-175.

Nielsen H, Engelbrecht J, Brunak S, Heijne G (1997) Identification of prokaryotic and eukaryotic signal peptides and prediction of their cleavage sites. Protein. Eng. Des. Sel. 10:1-6.

Pasentsis K, Falara V, Pateraki I, Gerasopoulos D, Kanellis AK (2007) Identification and expression profiling of low oxygen regulated genes from Citrus flavedo tissues using RT-PCR differential display. J. Exp. Bot. 58:2203-2216.

Paul V, Pandey R, Srivastava GC (2010) Ripening of tomato (Solanum lycopersicum L.). Part II: Regulation by its stem scar region. Association of Food Scientists \& Technologists 47:527-533.

Pegoraro C, Zanuzo MR, Chaves FC, Brackmann A, Girardi CL, Lucchetta $L$, et al (2010) Physiological and molecular changes associated with prevention of woolliness in peach following pre-harvest application of gibberellic acid. Postharvest Biol. Technol. 57:19-26.

Ramakrishna W, Deng ZP, Ding CK, Handa AK, Ozminkowski RH (2003) Anovel small heat shock protein gene, vis1, contributes to pectin depolymerization and juice viscosity in tomato fruit. Plant Physiol. 131:725-735.

Ramonell KM, McClure G, Musgrave ME (2002) Oxygen control of ethylene biosynthesis during seed development in Arabidopsis thaliana (L.) Heynh. Plant Cell Environ. 25:793-801.

Saeed Al, Sharov V, White J, Li J, Liang W, Bhagabati N, et al (2003) TM4: a free, open-source system for microarray data management and analysis. Biotechniques 34:374-378.

Sarkar NK, Kim Y, Grover A (2009) Rice sHsp genes: genomic organization and expression profiling under stress and development. BMC Gen. 10:393.

Song NH, Anh YJ (2011) DcHsp17.7, a small heat shock protein in carrot, is tissue-specifically expressed under salt stress and confers tolerance to salinity. New Biotech. 28:698-704.

Sun JH, Chen JY, Kuang JF, Chen WX, Lu WX (2010) Expression of sHSP genes as affected by heat shock and cold acclimation in relation to chilling tolerance in plum fruit. Postharvest Biol. Technol. 55:91-96.

Tadege M, Dupuis I, Kuhlemeier C (1999) Ethanolic fermentation: new functions for an old pathway. Trends Plant. Sci. 4:320-325.

Taylor NL, Tan YF, Jacoby RP, Millar AH (2009) Abiotic environmental stress induced changes in the Arabidopsis thaliana chloroplast, mitochondria and peroxisome proteomes. J. Proteomics 72:367-378.

Vidoz ML, Loreti E, Mensuali A, Alpi A, Perata P (2010) Hormonal interplay during adventitious root formation in flooded tomato plants. Plant J. 63:551-562.

Wang H, Schauer N, Usadel B, Frasse P, Zouine M, Hernould M, et al (2009) Regulatory features underlying pollination-dependent and independent tomato fruit set revealed by transcript and primary metabolite profiling. Plant Cell 21:1428-1452.

White PJ (2002) Recent advances in fruit development and ripening: an overview. J. Exp. Bot. 53:1995-2000. 
